\title{
Marine benthic invertebrates use multimodal cues for defense against reef fish
}

\author{
Raphael Ritson-Williams*, Valerie J. Paul \\ Smithsonian Marine Station at Fort Pierce, 701 Seaway Drive, Fort Pierce, Florida 34949, USA
}

\begin{abstract}
The use of bright coloration to warn predators of toxic prey, termed aposematism, is a defensive strategy well studied in terrestrial ecosystems. Some marine animals have contrasting color patterns and chemical defenses but few studies have tested the behavior of marine predators in response to aposematic coloration. In this study we tested fish feeding behavior in response to different types of cues including contrasting color patterns and sponge and nudibranch chemical extracts in the field at 2 reefs on Guam. Using agar-based food to keep food quality consistent, chemical extracts and 2 out of 5 contrasting color patterns reduced feeding by natural assemblages of reef fish at both reefs. Phyllidia varicosa (from Palau), P. elegans (Guam) and Phyllidiella pustulosa (Palau) crude extracts deterred feeding by fish, but $P$. pustulosa extracts from Guam did not. To determine if a chemical extract can act as an olfactory defense we videotaped fish behavior as they approached food containing nonpolar extracts of Acanthella cavernosa, the dietary sponge of Phyllidiella granulatus. Fish approached and then tasted the food with the chemical extract significantly less often than the control and the crude extract of another sponge Stylissa massa. In feeding assays with a contrasting color pattern combined with the chemical extract at natural concentrations, fish were deterred by the extract regardless of the color pattern. At half natural concentration only the chemical extract and the contrasting color pattern together significantly decreased fish feeding. Reef fish can use multimodal signals including visual, taste and olfactory cues to avoid marine benthic invertebrates.
\end{abstract}

KEY WORDS: Fish behavior · Multimodal signals · Aposematism - Phyllidiidae · Predator-prey interactions $\cdot$ Coral reef ecology $\cdot$ Marine chemical ecology

\section{INTRODUCTION}

Why animals would advertise their presence with contrasting color patterns has interested ecologists and evolutionary biologists for more than a century (Darwin 1859). Coloration can be used by organisms for many ecological functions including defense, to find a suitable mate, and to attract food. Aposematic coloration is the use of contrasting colors to warn predators of distasteful prey (Cott 1940). Even though brightly colored animals advertise their presence to potential predators, experimental evidence shows that contrasting color patterns can protect some insects better than cryptic color patterns (Sillen-Tullberg 1985). Most experimental studies have focused on terrestrial animals such as insects and snakes, in which contrasting color patterns deterred bird predators (Smith 1977 , Sillen-Tullberg 1985, Lindstrom et al. 1999) and some terrestrial invertebrate predators such as praying mantis and dragonflies (Bowdish \& Bultman 1993, Kauppinen \& Mappes 2003).

In marine habitats tropical fish are capable of seeing colors, have their maximum wavelength absorbance between blue and green wavelengths, and are probably capable of seeing up to red wavelengths (McFarland 1991). Fish are often the dominant visual predators on coral reefs, but few studies have tested the ability of fish to recognize, distinguish, and avoid color patterns. Research on aposematism in marine organisms has focused on brightly colored and chemi- 
cally defended taxa including flatworms and nudibranchs (Ang \& Newman 1998, Gosliner 2001, Gimenez-Casalduero et al. 2002). Many of these studies have concentrated on fish as predators but few of them experimentally tested whether color patterns independently influenced predator behavior. Cott (1940) stressed the importance of behavioral adaptations such as diurnal activity and gregariousness in order that warning coloration be an effective defense. Nudibranchs are good experimental models to test fish avoidance behavior since they are diurnal, slowmoving benthic animals that have lost their shell and instead are often chemically defended (Faulkner \& Ghiselin 1983, Brunkhorst 1991). Edmunds (1991) identified 4 criteria for determining aposematism in marine animals: (1) the animal must be toxic enough to be protected from predation; (2) the animal is brightly colored; (3) predators can learn to avoid the color pattern ${ }_{i}(4)$ conspicuous coloration will provide better protection than cryptic coloration.

An ecological trait that confers a selective advantage for survival such as aposematic coloration (Sillen-Tullberg 1985) should be effective in both terrestrial and marine systems, but there is a lack of experimental evidence on the variety of visual predators that respond to aposematic signals (Mappes et al. 2005). In addition, recent work with multiple terrestrial animals including monkeys, birds, and insects has shown that multiple cues presented together (termed multimodal cues) are more effective in communication than any 1 cue alone (Partan \& Marler 1999). To better understand the suite of defensive signals that tropical marine invertebrates might use against fish we conducted this study in the field with natural assemblages of reef fish on 2 reefs on Guam. We experimentally tested the effectiveness of visual, taste and olfactory defenses against fish predators by asking the following questions: (1) Are contrasting color patterns eaten less than solid colors? (2) Do secondary metabolites protect some sponges and nudibranchs from predation? (3) Do fish use olfactory cues to avoid potential food? (4) Are visual and chemical defenses more effective individually, or together?

\section{MATERIALS AND METHODS}

Species. The dorid nudibranch family Phyllidiidae contains over 49 species of nudibranchs distributed throughout the Indo-Pacific (Brunckhorst 1993). Most phyllidiid nudibranchs have contrasting color patterns, and many species (although most remain untested) sequester isocyanide terpenes and related compounds from their host sponges (Chang \& Scheuer 1993, Dumdei et al. 1997). Most phyllidiid species are uncommon on Guam, but we collected enough indi- viduals of Phyllidia elegans and Phyllidiella pustulosa from Guam and Phyllidia varicosa and Phyllidiella pustulosa from Palau for replicated feeding assays. Of the 10 phyllidiid species found on Guam, only Phyllidiella granulatus was consistently found eating the sponge Acanthella cavernosa. Because phyllidiid species were relatively rare and this sponge was abundant in certain habitats, we used the nonpolar crude extract of this sponge, which contains the same isocyano sesquiterpenes and diterpenes (Chang et al. 1984, Patra et al. 1984) as P. granulatus, for some of the feeding assays.

Chemical extractions and comparison. Individual phyllidiid nudibranchs and the sponge Acanthella cavernosa were hand-collected from various subtidal locations around Guam and Palau. All nudibranchs and sponges were immersed in a graduated cylinder with seawater to measure volume, and then blotted dry and weighed before being frozen or prepared for immediate extraction. Prior to extraction individual Phyllidiella granulatus were 'milked' (prodded with a spatula) for mucus and then dissected, separating the mantle from the foot (which included the visceral organs). Individual A. cavernosa were blended for $30 \mathrm{~s}$ to improve extraction efficiency. All specimens (including the nudibranch mucus) were covered and soaked in ethyl acetate for $24 \mathrm{~h}_{\text {; }}$ the ethyl acetate was decanted from the specimens and replaced with fresh solvent for another $24 \mathrm{~h}$. Ethyl acetate was selected for extractions because it effectively extracted nonpolar terpenes from the nudibranchs and sponge without also extracting polar metabolites that would not be related to these isocyano terpenes. The successive extracts were pooled for each specimen and then concentrated under vacuum. After extraction the specimens were dried at $60^{\circ} \mathrm{C}$ and weighed. The extract yields were calculated as grams of extract per total dry weight (including extract weight), wet weight, and volume of each specimen. P. granulatus and A. cavernosa crude extracts were compared using a HewletPackard 5890 Series II plus gas chromatograph-mass spectrometer (GC-MS) with a cross-linked $5 \%$ methyl silicone column (HP-5, $30 \mathrm{~m} \times 0.25 \mathrm{~mm})$. Extracts were diluted to $1 \mathrm{mg}$ of crude extract in $1 \mathrm{ml}$ of $3: 1$ hexanes:ethyl acetate. One $\mu \mathrm{l}$ of each sample was injected into the GC-MS in the splitless mode with an inlet pressure of $13.9 \mathrm{kPa}$ at $70^{\circ} \mathrm{C}$. The injection port was held at $250^{\circ} \mathrm{C}$ with a 70 to $290^{\circ} \mathrm{C}$ temperature ramp at $10^{\circ} \mathrm{C} \mathrm{min}^{-1}$. The carrier gas was helium at a flow rate of $0.5 \mathrm{ml} \mathrm{min}^{-1}$. A complete run through the GC-MS took 35 min as shown in Fig. 1.

Feeding experiments. To determine if Phyllidiella granulatus were eaten by reef fish, 5 small live $P$. granulatus were collected from Tanguisan reef (Guam) and then offered to fish at Fingers Reef (Guam, GPS = 


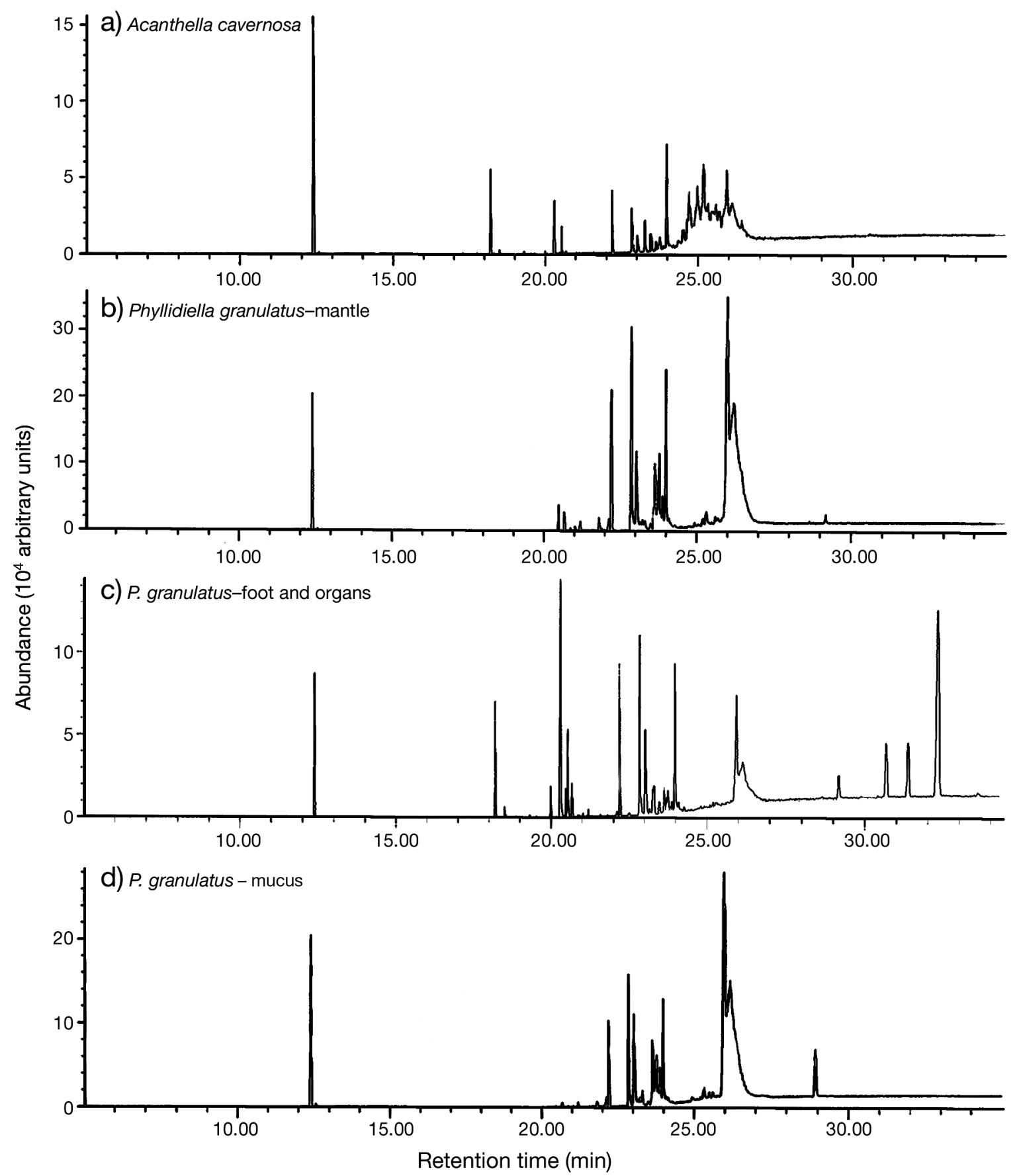

Fig. 1. Comparison of gas chromatography-mass spectrometry (GC-MS) traces of crude extracts (CE) from sponge Acanthella cavernosa and phyllidiid Phyllidiella granulatus. (a) GC-MS trace of CE of A. cavernosa; (b) trace of mantle CE of $P$. granulatus; (c) trace of CE of foot and organs of P. granulatus; (d) trace of CE of mucus of P. granulatus

$\left.13^{\circ} 26.695^{\prime} \mathrm{N} ; 144^{\circ} 38.198^{\prime} \mathrm{E}\right)$ alternately with a control of a similar sized piece of agar food (see next paragraph). The nudibranchs and food pellets were scored as eaten or not eaten, and these results were analyzed by Fisher's exact test.

To test color patterns and chemical defenses against fish predators we designed an agar-based food to keep food quality constant in every feeding experiment. The agar food pieces were the same general shape and size as nudibranchs and were made of $10 \mathrm{~g}$ of ground catfish food (Cargill Aquafeed), $5 \mathrm{~g}$ of carrageenan (Sigma C-1013), 2 g agar (Sigma A-7002), and $160 \mathrm{ml}$ of seawater (Gimenez-Casalduero et al. 1999). This recipe was chosen to match the approximate dry mass to vol- 
ume ratio and protein content of Phyllidiella granulatus. These ingredients were mixed and heated in a microwave oven for $120 \mathrm{~s}$. The hot mixture was poured into a plexiglass mold that formed 2 strips of food, $2 \times$ $35 \mathrm{~cm}$; these strips were cut into $2 \times 5 \mathrm{~cm}$ rectangles and used immediately or refrigerated overnight. Feeding assays were conducted in the field at Fingers Reef and at Gun Beach (Guam, GPS $=13^{\circ} 31.460^{\prime} \mathrm{N}_{\text {; }}$ $144^{\circ} 48.101^{\prime} \mathrm{E}$ ) at a constant depth of $7 \mathrm{~m}$. At both sites multiple (5 to 20) individuals of the following fish species were observed (using SCUBA) feeding on the agar food: Abudefduf sexfasciatus and A. vaigiensis (Pomacentridae), Cheilinus fasciatus, Thalassoma lutescens and T. hardwickii (Labridae), and Naso vlamingii (Acanthuridae). At Gun Beach, Bodianus axillaris (Labridae) also ate the food.

Color patterns. Feeding assays with color patterns covering the agar food were used to test the deterrent effect of a color pattern without chemical defense. By pairing a contrasting pattern with a cryptic pattern or a solid color we could test whether contrasting patterns were eaten less than cryptic patterns. Patterns included colored stripes, spots, and circles, which are similar to some naturally occurring phyllidiid color patterns (Fig. 2). As an initial comparison we used 2 color patterns (Fig. 2, mottled Patterns 1 and 2) that resembled the benthos on a reef, i.e. crustose coralline algae and turf algae. To control for a possible deterrence of a bright color alone we used a solid pattern of the dominant color for the remaining experiments (Fig. 2, solid colors, Patterns 3 to 5). To make the food, a paper 'skin' was placed on the agar food mixture while it was still hot. This skin consisted of a $2 \times 5 \mathrm{~cm}$ rectangle cut out of a color photocopy of the color pattern (Fig. 2). The paper skin had slots cut every $1 \mathrm{~cm}$ so that thin pieces of the paper could be folded down into the liquid gel to hold the paper in place. After the artificial food solidified, the paper skin was cut into $101 \times 1 \mathrm{~cm}$ squares, which allowed fish to remove bite-sized pieces of paper without tearing off the entire skin. Artificial foods with cryptic and contrasting color patterns were paired on ceramic tiles $(10 \times 10 \mathrm{~cm})$, which were covered with 1 of 2 laminated color patterns (Fig. 2, extreme left), and placed on the benthos (Fig. 3). The artificial food was attached to the surface of the laminated patterns on the tiles using paper clips bent into the shape of a hook to hold them in place. Both tile background color patterns were offered to fish at the same time. In this way the contrasting color patterns were simultaneously tested either contrasting or matching their background (Fig. 3). We used 15 replicates of paired food on a tile for each assay, except for the first experiment in which 1 replicate was lost. The percentage eaten (in area) of each artificial food cube was recorded in the field to the nearest $5 \%$. Individual replicates were stopped before one of the pair was completely eaten or when the paper skin was pulled off the food cube. The amount eaten of each pair of artificial food cubes on a tile was arcsine square-root transformed and then analyzed by a paired sample directed $t$-test $(\gamma / \alpha=0.8$, Rice \& Gaines 1994). Based on our a priori assumption that contrasting color patterns would be eaten less than solid color patterns we use directed p-values as described by Rice \& Gaines (1994).

Nudibranch extracts. To determine if phyllidiid species were chemically defended we tested crude ethyl acetate extracts, at natural concentrations, of each of the following species: Phyllidia elegans and Phyllidiella pustulosa from Guam, and Phyllidia varicosa and Phyllidiella pustulosa from Palau. We pooled together multiple individuals from the same species to have enough extract for replicate feeding assays. The crude extracts were dissolved in a minimal amount of ethyl acetate and added to the gel mixture while it was still warm. The gel mixture with crude extracts was poured into the molds as described above, but without a paper skin. The gel was cut into $2 \times 5 \mathrm{~cm}$ squares. Each extract treatment was paired with a control food with the same amount of ethyl acetate but no crude extract added. Ten replicates of the treatment and control food were placed together on a tile with a red background (Fig. 2, Pattern 3, solid red color) to standardize the background in the field at Gun Beach. The proportion eaten of each food was recorded and then arcsine square-root transformed and compared using a paired sample $t$-test (2-tailed).

Sponge extracts. Since phyllidiid nudibranchs are relatively rare and it was impossible to get enough crude extract to perform our experiments with the appropriate replicates, we used the nonpolar crude extract of Acanthella cavernosa (the dietary sponge of Phyllidiella granulatus) to test some of the basic assumptions of aposematic theory. To ensure that the sponge nonpolar extract was a feeding deterrent, A. cavernosa extract without color patterns was incorporated into the artificial food at a concentration of $2 \%$ dry weight and offered to reef fish. Crude extracts were dissolved in $7 \mathrm{ml}$ of ethyl acetate and added to the liquid gel mixture while still warm. The gel mixture with crude extracts was poured into the molds as described in the foregoing subsection, but without a paper skin. The gel was cut into $2 \times 5 \mathrm{~cm}$ squares. The control artificial food was made with $0.04 \mathrm{ml}$ of red food color (to control for the orange color of the A. cavernosa extract) and $7 \mathrm{ml}$ of ethyl acetate (to control for the presence of the solvent). Agar-based food with A. cavernosa extract was paired with a control and offered to reef fish ( $\mathrm{n}=10$ unless more extract was available) on tiles with a red background (Fig. 2 , 

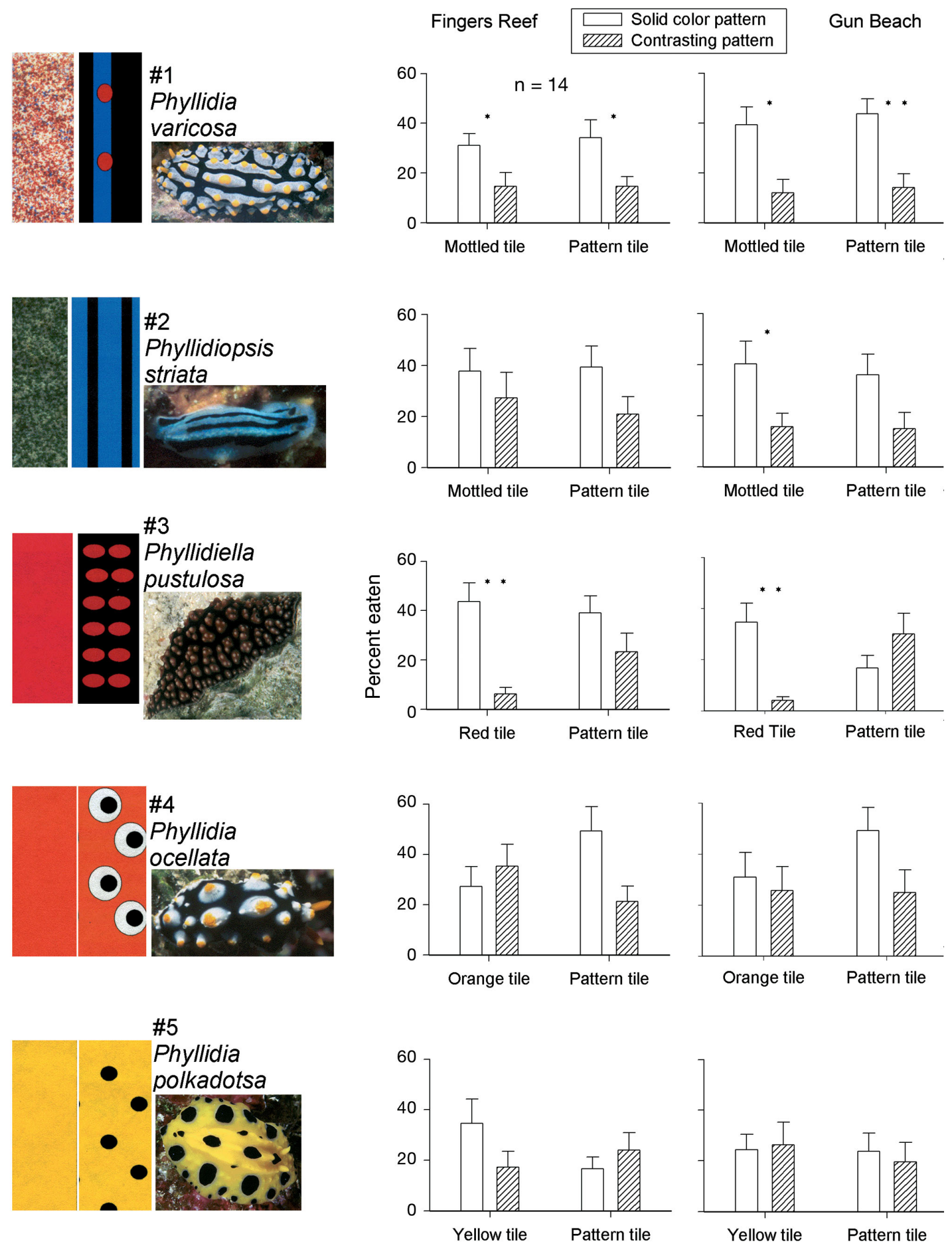

Fig. 2. Color pattern in feeding assays. Bars in graphs represent mean $(+1 \mathrm{SE})$ percentage of artificial food eaten by fish; tile color corresponds to color pattern on extreme left of relevant graph; open bars: food with cryptic pattern (i.e. covered with solid-color paper 'skin'); hatched bars: agar food covered with relevant contrasting pattern; *: statistically significantly less food with contrasting color pattern eaten than food with solid color (directional paired $t$-test, $\mathrm{p}<0.05$ ); $* *$ : $\mathrm{p}<0.01 ; \mathrm{n}=15$ unless otherwise noted 


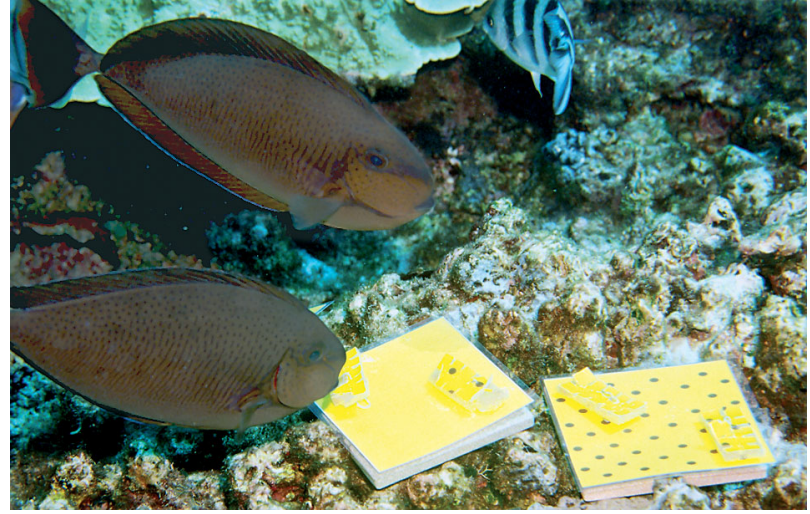

Fig. 3. Color pattern fish-feeding assay at Gun Beach, Guam. Color patterns of paired agar food offered to fish either matched or contrasted with background tiles

Pattern 3, solid red color). The proportion eaten of the artificial food cubes was recorded in the field, arcsine square-root transformed and then analyzed by a paired sample $t$-test (2-tailed). Serial dilutions $(2,1$, $0.5,0.2,0.1$, and $0.02 \%$ by dry weight) of the crude extract were tested to find the threshold concentration that deterred feeding by reef fish.

Olfactory cues for prey avoidance. Field observations of the feeding assays with Acanthella cavernosa crude extracts suggested that fish were deterred from the food before tasting it. To test whether reef fish perceived compounds by olfaction without tasting the agar food we videotaped 2 feeding assays to quantify fish behavior. Paired food cubes were offered to fish at Fingers Reef on a tile with a red laminated cover. The treated food contained $A$. cavernosa extract at a concentration of $2 \%$ dry weight and was paired with either control food that contained $0.04 \mathrm{ml}$ red food color and ethyl acetate, or (in a separate assay) the extract of another orange sponge Stylissa massa (natural concentration $=7.4 \%$ dry weight) that contains more polar, deterrent natural products (Becerro et al. 2003). The color of the control and the Stylissa massa crude extract were practically indistinguishable from the food with $A$. cavernosa extract. The results were scored for the percentage of approaches that resulted in a bite. A fish had to swim toward and be within a $10 \mathrm{~cm}$ radius of the food to be scored as an approach. Repeat bites on the same approach were scored as 1 approach and bite. The proportion of approaches that resulted in a bite of $A$. cavernosa extract versus the solvent control and $A$. cavernosa extract versus $S$. massa extract were arcsine square-root transformed and compared using a paired $t$-test (2-tailed).

Color pattern combined with chemical defense. Feeding assays with both color patterns and crude extract were conducted at Fingers Reef to determine whether a combination of color patterns and crude extract would more efficiently deter fish from feeding than either of these used individually. Gray ceramic tiles $(15 \times 15 \mathrm{~cm})$ with 2 bent paper clips attached directly to the tiles with waterproof epoxy (PC-7) were used as the background for these experiments. The experiment was conducted twice, first with Acanthella cavernosa crude extract at $2 \%$ dry weight, and (on a different day) at a concentration of $1 \%$ dry weight. Agar-based food had skins that matched the tile (gray) or contrasted with it (gray with red dots, similar to Contrasting Pattern 3, Fig. 2). Red food color and ethyl acetate were added to all of the agar food without A. cavernosa extract, including the control. There were 4 treatments: gray food, gray food with crude extract, contrasting food, and contrasting food with crude extract. Artificial agar food was offered in pairs on each tile, with the gray food without extract as the control in every treatment. Four observers scored the percentage of each food cube eaten; each observer scored 5 replicates of all 4 treatments to control for possible observer bias. Of the 20 replicates for each treatment, 2 were not included in the analysis since they lost their skin before either artificial food was tasted. To determine any difference between the amount eaten of the control and the various treatments, the data were arcsine square-root transformed and analyzed by a paired $t$-test (2-tailed).

\section{RESULTS}

Sponge and nudibranch chemical comparison. Phyllidiella granulatus and Acanthella cavernosa crude extracts contained some of the same major metabolites, although relative proportions differed somewhat among nudibranch tissues (Fig. 1). Sponge compounds were found throughout the nudibranch body regions including the mucus (Fig. 1d). All 6 individual $P$. granulatus found feeding on $A$. cavernosa had similar GC-MS traces as their dietary sponge, but here we present only 1 example for clarity. The extracts contained kalihinol A and C (peaks at 25.9 and $22.8 \mathrm{~min}$, respectively), 2 di-isocyano diterpenes previously isolated and characterized from Acanthella cavernosa (Chang et al. 1984, Patra et al. 1984), and a sesquiterpene isocyanide compound (peak at $12.4 \mathrm{~min}$ ) with a mass spectrum indicating similarity to the epimaaliane series isolated from the sponge Axinella cannabina (Chang \& Scheuer 1993). Individual A. cavernosa extract yields ranged from 0.7 to $6 \%$ of the sponge dry weight. The mean extract yield for $A$. cavernosa was $2.9 \% \pm 0.5 \mathrm{SE}(\mathrm{n}=4)$ by dry weight, $0.5 \% \pm 0.1 \mathrm{SE}$ wet weight and $0.004 \pm 0.001 \mathrm{SE}\left(\mathrm{g} \mathrm{ml}^{-1}\right)$ volume. $P$. granulatus mantle was $8.4 \% \pm 3.1 \mathrm{SE}(\mathrm{n}=5)$, and mucus 
was $13.7 \% \pm 5.7 \mathrm{SE}(\mathrm{n}=6)$ by dry weight. Mean concentrations of extract in the nudibranch mantle were $0.017\left(\mathrm{~g} \mathrm{ml}^{-1}\right)$ volume and $2.7 \%$ wet weight, both of which are more concentrated than our experimental concentration of $0.002\left(\mathrm{~g} \mathrm{ml}^{-1}\right)$ volume and $0.2 \%$ wet weight. A concentration of $2 \%$ A. cavernosa extract per dry weight was used for most feeding assays since we were limited by the amount of sponge extract that we could obtain and because the extract was such a potent feeding deterrent. An experimental concentration of $2 \%$ dry weight of the crude extract is a conservative concentration for both sponges and nudibranchs.

Feeding experiments. There was a significant difference in the number of live Phyllidiella granulatus nudibranchs versus agar food eaten $(\mathrm{n}=5, \mathrm{p}<0.01)$. None of the live $P$. granulatus were eaten, but 3 individuals were mouthed and then rejected, and all of the control agar pieces were eaten. While this experiment showed that the nudibranchs were protected from a natural assemblage of reef fish, it did not show whether the nudibranch's color pattern or chemical defense was responsible for this predator deterrence.

Color patterns. Natural assemblages of reef fish had variable responses to the different color patterns tested (Fig. 2). Pattern 1 was deterrent at both sites on both tile backgrounds (Fig. 2). Pattern 2 was only deterrent at Gun Beach on the green mottled background. Pattern 3 was deterrent at both locations on the solid red background, but was not deterrent on the matching background. Patterns 4 and 5 were never deterrent.

Nudibranch extracts. Three of the 4 tested phyllidiid spp. crude extracts were deterrent (Fig. 4, n = 10, p < 0.01). The crude extract of Phyllidiella pustulosa from Guam was not deterrent but the same species from Palau did reduce feeding. In a comparison of their GCMS traces the nudibranchs from each island contained different secondary metabolites (data not shown), suggesting either their sponge diets were different or their sponge prey produced different compounds on different islands.

Sponge extracts. At less than natural concentrations, the crude extracts of Acanthella cavernosa deterred fish feeding at both reefs (Fig. 5). At Fingers Reef, the crude extract deterred feeding by reef fish at $1 \%$ dry weight, but not at lower concentrations. At Gun Beach, the extract deterred feeeding at $0.2 \%$ dry weight $(10 \%$ of our experimental concentration and $2.4 \%$ of natural nudibranch concentration).

Olfactory cues for prey avoidance. Fish approached and then tasted the artificial food with Acanthella cavernosa crude extract significantly less frequently than the paired control (Fig. 6, $\mathrm{n}=12$, $\mathrm{p}<0.01$ ). When paired with another sponge extract, A. cavernosa was approached and then tasted significantly less often than the food with Stylissa massa extract added (Fig. 6, n = 10, p < 0.01).
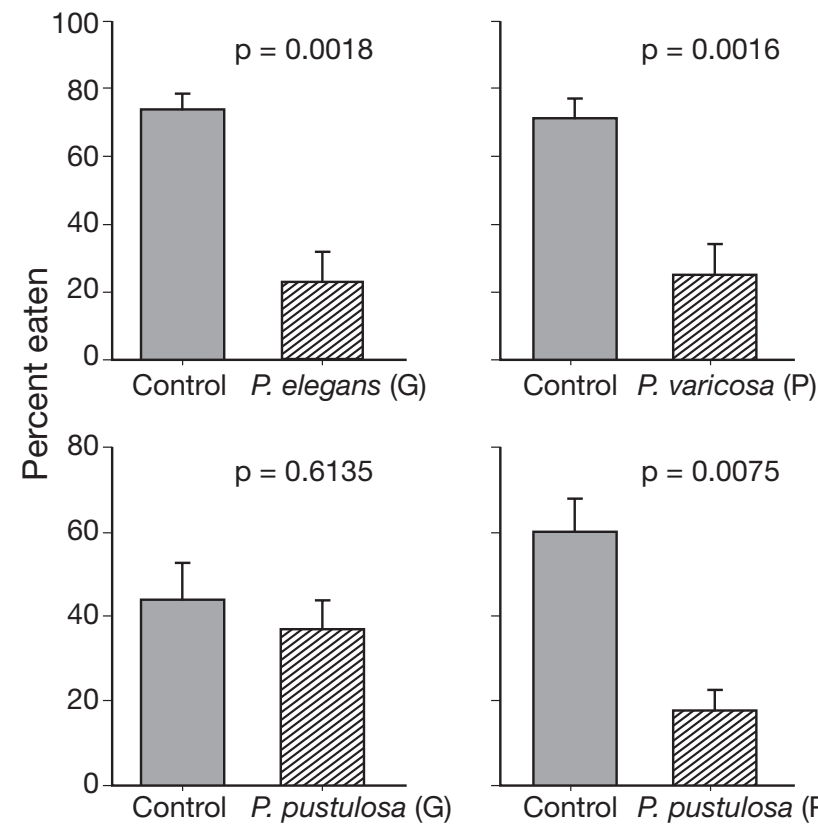

Fig. 4. Phyllidia elegans, P. varicosa, Phyllidiella pustulosa from Palau (P) and Guam (G). Nudibranch crude extract (CE) feeding assays showing mean (+1SE) percentage of artificial food eaten by fish. In all replicates, control food (gray bars) was paired with nudibranch CE incorporated into food (hatched bars). Data analyzed by paired-sample $t$-tests (2-tailed); $\mathrm{n}=10$ for all assays

Color pattern combined with chemical defense. When crude extracts ( $2 \%$ dry weight) and color patterns were tested together the 2 treatments containing Acanthella cavernosa crude extract were eaten significantly less often than their paired controls (Fig. 7a). There was no deterrent effect of the color pattern alone. When the compounds were tested at $1 \%$ dry weight the only treatment that had a significant effect on the amount eaten was the combination of crude extract and the contrasting pattern (Fig. 7b). Independently, neither the crude extracts nor the color pattern deterred fish feeding.

\section{DISCUSSION}

Aposematic coloration is a known defensive mechanism against birds and some insects in terrestrial ecosystems, but few experiments have tested aposematic coloration against fish, the dominant visual predators in marine ecosystems. For soft-bodied animals such as nudibranchs to deter visual predators it may be advantageous to advertise their distastefulness with bright color patterns. We have shown that natural assemblages of reef fish are capable of detecting and avoiding visual, taste and olfactory defensive cues produced by benthic organisms and that these cues can be more effective together instead of independently. 

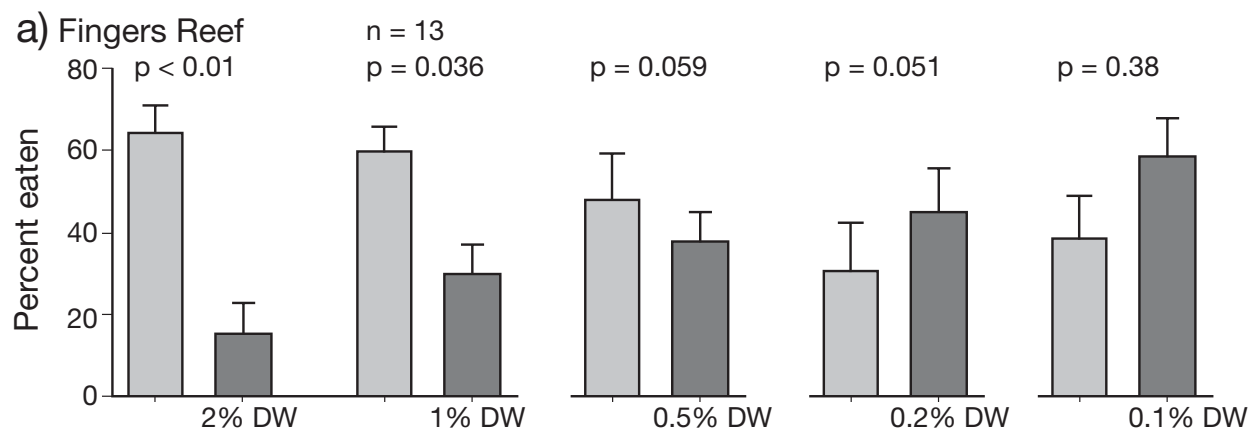

$p=0.36$
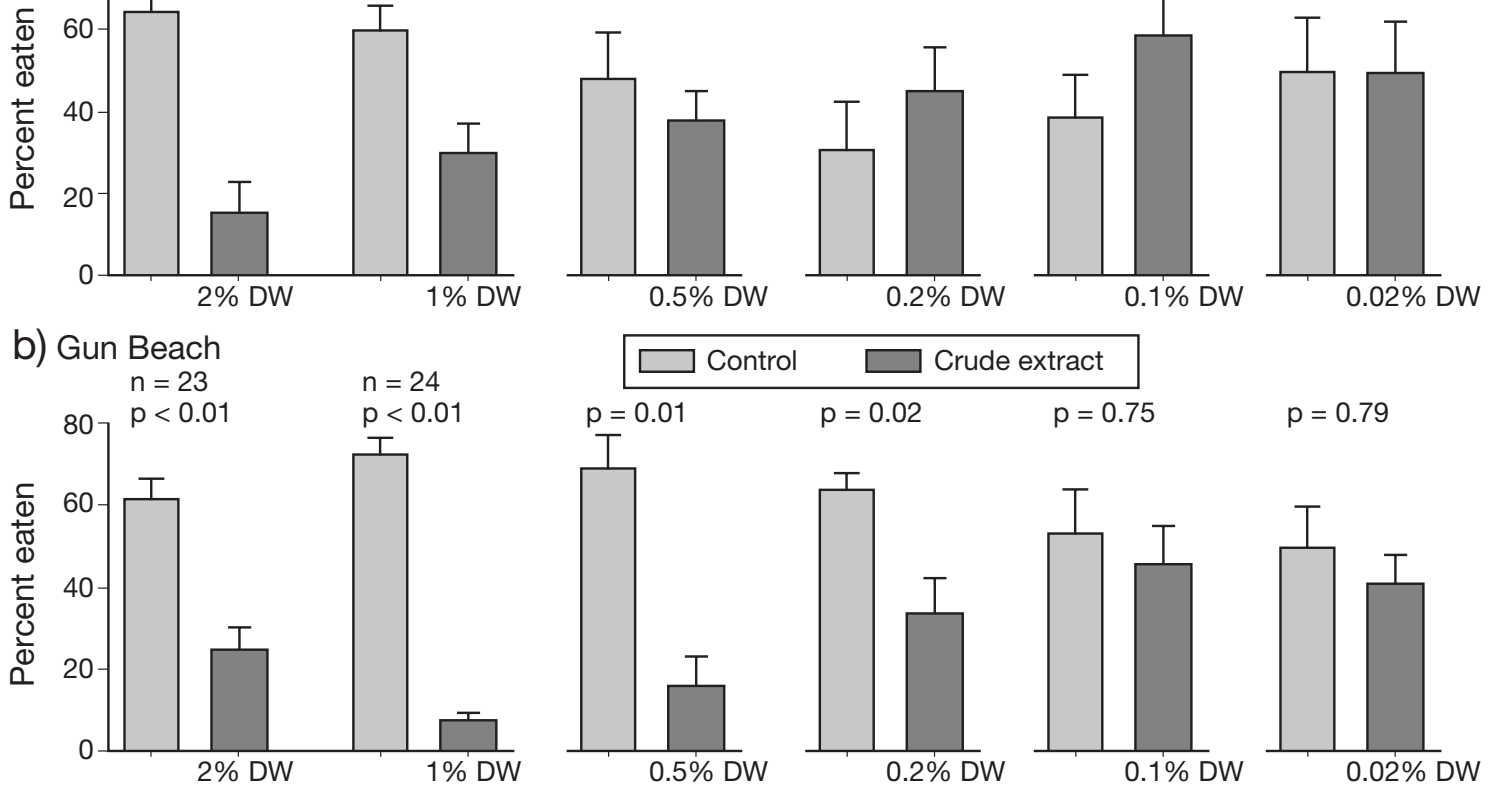

Fig. 5. Acanthella cavernosa. Crude extract (CE) feeding assays showing mean (+1SE) percentage of artificial food eaten by fish at (a) Fingers Reef and (b) Gun Beach, Guam. In all replicates, control food (light gray bars) was paired with serial dilutions of CE (\% dry weight of artificial food) incorporated into the food (dark gray bars). Data analyzed by paired-sample $t$-test (2-tailed); DW: dry weight; $\mathrm{n}=10$ unless otherwise noted

Many benthic coral reef organisms have bright color patterns, but the function of these color patterns has rarely been tested (Gosliner \& Behrens 1990, Pawlik et al. 1995). The present study has shown that fish avoided some but not all contrasting color patterns, independent of a chemical defense (Fig. 2). This is also true in terrestrial ecosystems where some birds have

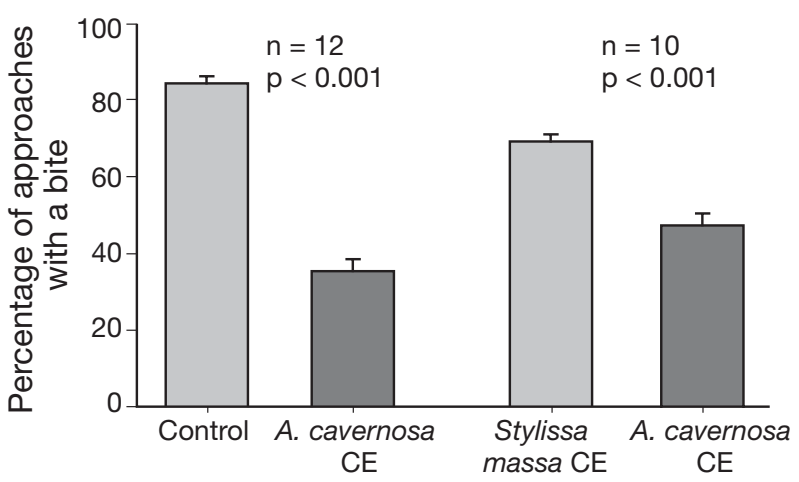

Fig. 6. Olfactory cues for prey avoidance showing mean (+1SE) percentage of fish approaches that resulted in bite of the food (Acanthella cavernosa or Stylissa massa). Fish were considered as approaching food if they swam toward and within $10 \mathrm{~cm}$ of it. A. cavernosa extract was offered at $2 \% \mathrm{DW}$ of food, $S$. massa extract was offered at natural concentration (7.4\% DW). Data analyzed by paired-sample $t$-test (2- tailed) CE: crude extract an innate avoidance of coral snake color patterns (Smith 1977). In terrestrial systems, some animals mimic the successful patterns, which is an adaptation that can improve the chances of survival for a mimic with or without chemical defenses (Kapan 2001). On coral reefs color patterns similar to those of phyllidiid nudibranchs can be found in other gastropods, sea cucumbers, and flatworms (Gosliner \& Behrens 1990, Newman et al. 1994). Further experimental studies of aposematism in the marine environment could reveal the evolutionary advantage of some color patterns which have evolved into mimicry systems between a variety of marine phyla (not just between species within an order, e.g. butterflies).

The function of bright colors in the marine environment is still poorly understood, for instance in a previous study no correlation of bright colors and predator deterrence was found in sponges (Pawlik et al. 1995), but another study did find a significant correlation of bright colors and unpalatablity in marine worms (Kicklighter \& Hay 2006). In our study, the contrasting color Pattern 1 (similar to that of Phyllidia varicosa) was deterrent on both background tiles, but Pattern 3 was only deterrent when it was offered in contrast to the solid red background (Fig. 2). This pattern is similar to that of Phyllidiella pustulosa, the most common phyllidiid nudibranch found on Guam (R. Ritson-Williams 


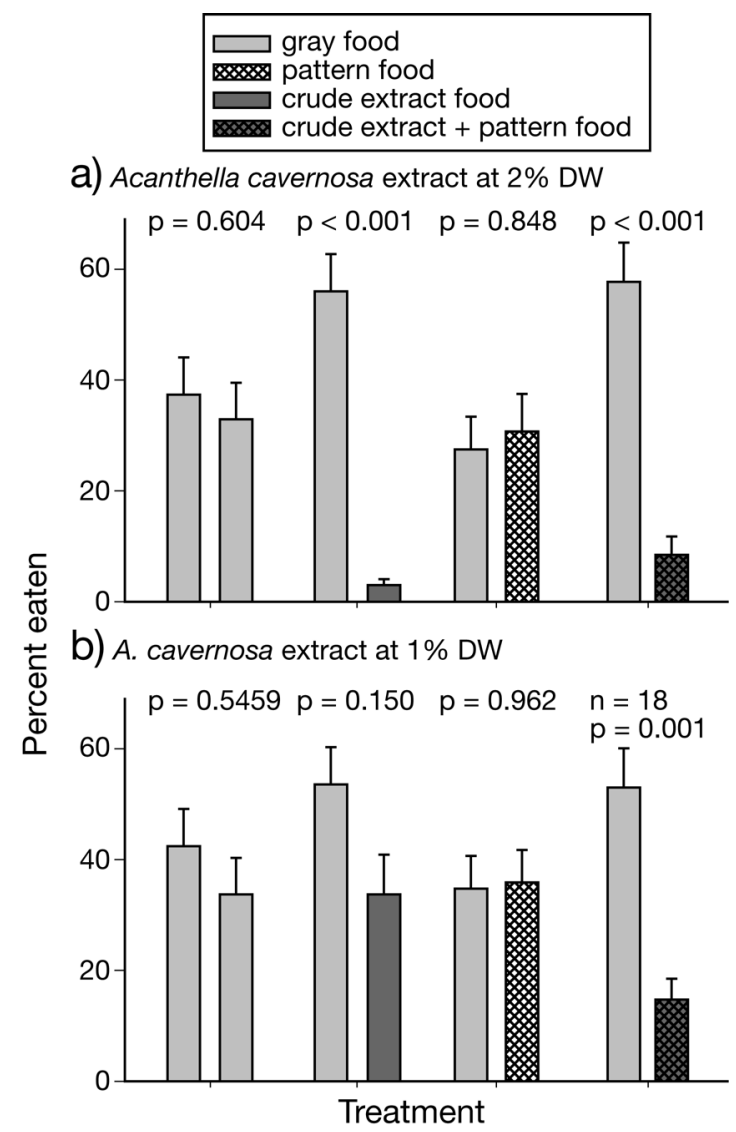

Fig. 7. Color pattern combined with chemical-defense feeding assays showing mean (+1SE) amount of artificial food eaten by fish. Gray food: gray color pattern (matching background); pattern food: food covered with contrasting color pattern (gray with red spots); crude extract food: crude extract added to food, which was covered with matching pattern; crude extract + pattern food: crude extract covered by contrasting pattern. (a) and (b) both conducted at Fingers Reef, but at different times with different concentrations of Acanthella cavernosa crude extract. Data analyzed by pairedsample $t$-test (2-tailed); $\mathrm{n}=20$ unless otherwise noted

pers. obs.). Possibly, fish on Guam have learned to avoid these patterns from experience. Patterns similar to those of Phyllidia ocelata and P. polkadotsa (Patterns 4 and 5 respectively) did not deter fish feeding on either background. These nudibranchs are not recorded from Guam and their color patterns are probably novel to these fish.

An important component of aposematism is that predators will remember brightly colored animals better than cryptic ones (Edmunds 1991). Previous marine studies found that fish could learn to avoid deterrent compounds (Long \& Hay 2006) and colored food with deterrent compounds added (Gimenez-Casalduero et al. 1999). Fish 'learning' is central to the effectiveness of aposematism, but key questions, such as duration of memory or innate avoidance, which are known for birds (Smith 1977, Roper \& Redston 1987, Lindstrom et al. 1999) remain unstudied for fish. The ability of fish to remember, and the role of continuous tasting and conditioning are important aspects of learning (Speed 2000) that could be tested using the methods presented in this study with individual fish.

Phyllidiella granulatus sequesters multiple compounds from its host sponge Acanthella cavernosa (Fig. 1). Other studies have found isocyanide and isothiocyanate compounds in various species of phyllidiid nudibranchs and their host sponges (Chang \& Scheuer 1993, Dumdei et al. 1997). These compounds are toxic to some animals (Johannes 1963, Gunthorpe \& Cameron 1987) and are components of the crude extracts that were deterrent in this study. In P. granulatus, sponge compounds are found in the mantle, the foot and internal organs, and the mucus (Fig. 1). Mucus is secreted from the mantle when these and other opisthobranchs are handled, suggesting a defensive role for this secretion (Johannes 1963, Becerro et al. 2001). By releasing mucus when touched, these nudibranchs have a mechanism for releasing concentrated lipophilic compounds, which could deter fish before they damage the nudibranchs.

Most of the phyllidiid species that we tested contained chemical defenses that reduced fish feeding (Fig. 4). Phyllidiella pustulosa from Guam was not chemically defended. Recent work on poison dart frogs has found a continuum of conspicuousness and toxicity, whereby highly conspicuous frogs were less toxic and highly toxic frogs were less conspicuous (Darst et al. 2006). This may be the case for P. pustulosa, which has a deterrent color pattern on a contrasting background (Fig. 2, Pattern 3) but variable chemical defense on different islands (Fig. 4), probably depending on its diet. On 1 island there was even a different response of fish to chemical defenses at 2 different reefs (Fig. 5). Biogeographical variation in secondary metabolites and predator behavior is an important consideration when testing defensive adaptations and deserves more experimental research.

The fish observed eating in the feeding assays avoided the treatments with Acanthella cavernosa crude extract added, often without tasting them. Fish have a sense of smell, for example tuna can distinguish the smell of different prey items (Atema et al. 1980). Fish olfaction is often studied in terms of conspecific chemical alarm cues (Hara 1993), and fish can learn that a novel olfactory cue signals danger from a predator (Larson \& McCormick 2005). In this study we have shown that $A$. cavernosa crude extract protected food even before it was tasted, probably through smell. Scheuer (1992) noted a distinct smell associated with the isocyanide compounds isolated from Phyllidia varicosa. No studies that we know of have shown that volatile compounds deter fish predation (Pawlik et al. 
2002); however the senses of taste and smell are not typically distinguished experimentally. In birds, pyrazine odor triggered an aversion to certain colors that were not avoided without the odor cue (Rowe \& Guilford 1996).

Multiple warning signals can induce a predator response that is not present when any one signal is presented alone (Rowe \& Guilford 1996). This type of multimodal signal is considered an emergent signal and has been studied in terrestrial organisms (Partan \& Marler 1999) but much less so in the marine environment. Our interaction experiment (Fig. 7) shows that crude extracts are a defensive signal alone, a dominant multimodal signal. However, at reduced concentration the extracts and color patterns work together to reduce feeding, an emergent multimodal signal (Partan \& Marler 1999). The marine environment is a unique ecosystem for studying the selective advantage of multimodal defensive traits in predators such as fish, which can be compared to birds to determine which traits benefit both marine and terrestrial organisms.

Some benthic organisms are well defended from fish predation and probably use a multimodal defensive strategy by combining visual, taste, and olfactory cues to deter their predators. In this study we have experimentally shown the defensive advantage of contrasting color patterns in the marine environment, which potentially protects many soft-bodied invertebrates from visual predators. Many recent studies of aposematism have focused on modeling the evolution of warning signals in terrestrial animals (Sherratt 2002, Endler \& Mappes 2004) but have not considered the impact of these signals on marine predators. As a widespread adaptation, future studies of aposematism should incorporate data from both marine and terrestrial ecosystems to evaluate the evolutionary origin and success of aposematic coloration.

Acknowledgements. Special thanks to the staff and students of the University of Guam Marine Laboratory and of the Palau Coral Reef Research Foundation who were invaluable in completing this research, especially L. Bell, V. Bonito, C. Carlson, R. Chang, P. Colin, B. Irish, L. Kirkendale, and A. Palmer. Thanks also to Drs. M. Becerro, K. Clifton, G. Denton, T. Donaldson, R. Thacker, and L. Yudin for their help with experimental design and statistics and to John Hoover for the use of his photograph of Phyllidia polkadotsa. This manuscript was greatly improved by comments from Drs. G. Cronin, M. T. Ghiselin and 3 anonymous reviewers. A Sigma Xi Grant in Aid of Research and a Lerner Gray grant from the American Museum of Natural History to R.R.W. partially funded this research. This work was completed in partial fulfillment of the requirements for a M.Sc. degree by R.R.W. and is Contribution No. 596 of the University of Guam Marine Laboratory, and Contribution No. 695 of the Smithsonian Marine Station at Fort Pierce. All collections and experiments were conducted according to the Guam Department of Agriculture, Division of Aquatic and Wildlife Resources regulations.

\section{LITERATURE CITED}

Ang HP, Newman LJ (1998) Warning colouration in pseudocerotid flatworms (Platyhelminthes, Polycladia). A preliminary study. Hydrobiologia 383:29-33

Atema J, Holland K, Ikehara W (1980) Olfactory responses of yellowfin tuna (Thunnus albacares) to prey odors: chemical search image. J Chem Ecol 6:457-464

Becerro M, Goetz G, Paul VJ, Scheuer PJ (2001) Chemical defenses of the sacoglossan mollusk Elysia rufescens and its host alga Bryopsis sp. J Chem Ecol 27:2287-2299

Becerro M, Thacker RW, Turon X, Uriz MJ, Paul VJ (2003) Biogeography of sponge chemical ecology: comparisons of tropical and temperate defenses. Oecologia 135:91-101

Bowdish, TI, Bultman TL (1993) Visual cues used by mantids in learning aversion to aposematically colored prey. Am Midl Nat 129:215-222

Brunckhorst DJ (1991) Do phyllidiid nudibranchs demonstrate behavior consistent with their apparent warning coloration? - some field observations. J Molluscan Stud 57: $481-489$

Brunckhorst DJ (1993) The systematics and phylogeny of phyllidiid nudibranchs (Doridoidea). Rec Aust Mus Suppl 16:1-107

Chang C, Scheuer PJ (1993) Marine isocyano compounds. Top Curr Chem 167:33-75

Chang C, Patra A, Roll D, Scheuer PJ, Mastsumoto GK, Clardy J (1984) Kalihinol-A, a highly functionalized diisocyano diterpenoid antibiotic from a sponge. J Am Chem Soc 106: $4644-4646$

Cott HB (1940) Adaptive coloration in animals. Methuen London

Darst CR, Cummings ME, Cannatella DC (2006) A mechanism for diversity in warning signals: conspicuousness versus toxicity in poison frogs. Proc Natl Acad Sci USA 103:5852-5857

Darwin C (1859) The origin of species by means of natural selection, or the preservation of favoured races in the struggle for life. J Murray, London

Dumdei EJ, Flowers A, Garson M, Moore C (1997) The biosynthesis of sesquiterpene isocyanides and isothiocyanates in the marine sponge Acanthella cavernosa (Dendy); evidence for dietary transfer to the dorid nudibranch Phyllidiella pustulosa. Comp Biochem Physiol 118: 1385-1392

Edmunds M (1991) Does warning coloration occur in nudibranchs? Malacologia 32:241-255

Endler JA, Mappes J (2004) Predator mixes and the conspicuousness of aposematic signals. Am Nat 163:532-547

Faulkner DJ, Ghiselin MT (1983) Chemical defense and evolutionary ecology of dorid nudibranchs and some other opisthobranch gastropods. Mar Ecol Prog Ser 13:295-301

Gimenez-Casalduero F, Thacker RW, Paul VJ (1999) Association of color and feeding deterrence by tropical reef fish. Chemoecology 9:33-39

Gimenez-Casalduero F, Muniain C, Garcia-Charton JA (2002) Elysia timida (Risso, 1818) (Gastropoda, Opisthobranchia): relationship and feeding deterrence to a potential predator on the south-western Mediterranean coast. Mar Biol 141:1051-1057

Gosliner TM (2001) Aposematic coloration and mimicry in opisthobranch mollusks: new phylogenetic and experimental data. Bull Malacol 37:163-170

Gosliner TM, Behrens DW (1990) Special resemblance, aposematic coloration and mimicry in opisthobranch gastropods. In: Wicksten M (ed) Adaptive significance of color in invertebrates. Texas A\&M University Press, College Station, TX, p 127-138 
Gunthorpe L, Cameron A (1987) Bioactive properties of extracts from Australian dorid nudibranchs. Mar Biol 94: $39-43$

Hara T (1993) Role of olfaction in fish behavior. In: Pitcher T (ed) Behavior of teleost fish, 2nd edn. Chapman \& Hall, London, p 171-199

Johannes R (1963) A poison-secreting nudibranch (Mollusca: Opisthobranchia). Veliger 5:104-105

Kapan D (2001) Three-butterfly system provides a field test of mullerian mimicry. Nature 409:338-340

Kauppinen J, Mappes J (2003) Why are wasps so intimidating: field experiments on hunting dragonflies (Odonata: Aeshna grandis). Anim Behav 66:505-511

Kicklighter CE, Hay ME (2006) Integrating prey defensive traits: contrasts of marine worms from temperate and tropical habitats. Ecol Monogr 76:195-215

Larson JK, McCormick MI (2005) The role of chemical alarm signals in facilitating learned recognition of novel chemical cues in a coral reef fish. Anim Behav 69:51-57

Lindstrom L, Alatao R, Mappes J (1999) Reactions of handreared and wild-caught predators toward warningly colored, gregarious, and conspicuous prey. Behav Ecol 10: $317-322$

Long JD, Hay ME (2006) Fish learn aversions to a nudibranch's chemical defense. Mar Ecol Prog Ser 307: 199-208

Mappes J, Marples N, Endler JA (2005) The complex business of survival by aposematism. Trends Ecol Evol 20: 598-603

McFarland W (1991) The visual world of coral reef fish. In: Sale P (ed) The ecology of fish on coral reefs. Academic Press, New York, p 16-36

Newman LJ, Cannon L, Brunckhorst DJ (1994) A new flatworm (Platyhelminthes: Polycladia) which mimics a phyllidiid

Editorial responsibility: Charles Birkeland (Contributing Editor), Honolulu, Hawaii, USA nudibranch (Mollusca, Nudibranchia). Zool J Linn Soc 110: $19-25$

Partan S, Marler P (1999) Communication goes multimodal. Science 283:1272-1273

Patra A, Chang C, Scheuer PJ, Van Duyne GD, Matsumoto GK, Clardy J (1984) An unprecedented triisocyano diterpenoid antibiotic from a sponge. J Am Chem Soc 106:7981-7983

Pawlik JR, Chanas B, Toonen RJ, Fenical W (1995) Defenses of Caribbean sponges against predatory reef fish. I. Chemical deterrency. Mar Ecol Prog Ser 127:183-194

Pawlik JR, McFall G, Zea S (2002) Does the odor from sponges of the genus Ircinia protect them from fish predators? J Chem Ecol 28:1103-1115

Rice WR, Gaines SD (1994) Heads I win, tails you lose: testing directional alternative hypotheses in ecological and evolutionary research. Trends Ecol Evol 9:235-237

Roper TJ, Redston S (1987) Conspicuousness of distasteful prey affects the strength and durability of one-trial avoidance learning. Anim Behav 35:739-747

Rowe C, Guilford T (1996) Hidden colour aversions in domestic chicks triggered by pyrazine odours of insect warning displays. Nature 383:520-522

Scheuer PJ (1992) Isocyanides and cyanides as natural products. Accounts Chem Res 25:433-439

Sherratt TN (2002) The coevolution of warning signals. Proc R Soc Lond B 296:741-746

Sillen-Tullberg B (1985) Higher survival of an aposematic than of a cryptic form of a distasteful bug. Oecologia 67: $411-415$

Smith SM (1977) Coral-snake pattern recognition and stimulus generalisation by naïve great kiskadees (Aves: Tyrannidae). Nature 265:535-536

Speed M (2000) Warning signals, receiver psychology and predator memory. Anim Behav 60:263-278

Submitted: August 3, 2006; Accepted: November 7, 2006

Proofs received from author(s): June 6, 2007 